\title{
Application of Synthetic Nanozeolite Sodalite in Drug Delivery
}

\author{
Shaghayegh Rahmani, *Seyed Naser Azizi, Neda Asemi \\ Faculty of Chemistry, University of Mazandaran, P.O. Box 47416-95447, Babolsar, Iran
}

\begin{abstract}
In this study nanozeolite sodalite was synthesized from natural volcanic glass (perlite) as silica ( $\mathrm{Si}$ ) source and sodium aluminate as aluminium (Al) source without using any organic template. We use perlite as $\mathrm{Si}$ source because it is cost-effective and available source. These nanoparticles of synthesized zeolite were prepared at $170^{\circ} \mathrm{C}$ in stainless steel reactor with hydrothermal method. The synthesized nanozeolite was characterized by X-ray diffraction (XRD), fourier transform infrared (FTIR) and scanning electron microscopy (SEM) techniques. Chemical composition of perlite was determined by X-ray fluorescence (XRF).This nanozeolite was modified with cationic surfactant, hexadecyltrimethylammonium bromide (HDTMAB). In this study adsorption of cetirizine (Cet) as a model drug onto nanozeolite sodalite as a carrier of drug was investigated and Ultra Violet-Visible (UV-Vis) spectrophotometry was used for determination of concentrations of Cet at $230 \mathrm{~nm}$. Adsorption characteristics of Cet on nanozeolite sodalite were examined at different times $(0-6 \mathrm{~h})$ and also the analysis was carried at three $\mathrm{pH}$ levels 4,5 and 6 . Finally three buffered solutions with different $\mathrm{pH}(1.2,6.8$ and 7.2$)$ were selected for release medium and the temperature was precisely controlled at $37 \pm 0.1^{\circ} \mathrm{C}$.
\end{abstract}

Key Words: Carrier, cetirizine, loading, release, modification, perlite.

\section{INTRODUCTION}

Nanocarriers with optimized physicochemical and biological properties are taken up by cells more easily than larger molecules, so they can be successfully used as delivery tools for currently available bioactive compounds (Suri et al., 2007). Liposomes, solid lipids nanoparticles, dendrimers, polymers, silica materials, carbon materials, and magnetic nanoparticles are the examples of nanocarriers that have been tested as drug delivery systems (Wilczewska and Pavelic, 2012).

Several toxicological studies proved that zeolites such as natural clinoptilolite are nontoxic and safe materials for use in human and veterinary medicine (Kralj et al., 2003). Zeolites are microporous crystalline aluminosilicates that contain alkaline metal ions and water molecules. They are based on a three-dimensional framework of $\mathrm{SiO}_{4}$ and $\mathrm{AlO}_{4}$ tetrahedral that results in an extended uniform network of channels and pores (Rimoli et al., 2008). Zeolites have been extensively used in various industrial applications based on their properties to act as catalysts, ion exchangers, adsorbents, and detergent builders (Pavelic, 1980; Sersale, 1985; Naber et al., 1994; Garces, 1999; Colella, 1999). By virtue of these unique properties, they can absorb large amounts of molecules both in the gas and in liquid phases, facilitate ion exchange, and act as molecular sieves (Kralj et al., 2003).

Cetirizine (Cet), figure 1, is a long acting antihistamine with some mast-cell stabilizing activity which is known as 1-(2-(carboxymethyl) ethyl)-4-(4-chlorobenzhydryl) piperazinium dichloride (trade name Zyrtec) and widely used in the comprehensive management of allergic rhinitis, the symptoms of which include itching, sneezing and nasal congestion. Its molecular formula is $\mathrm{C}_{21} \mathrm{H}_{27} \mathrm{C}_{13} \mathrm{~N}_{2} \mathrm{O}_{3}$ and is rapidly absorbed with the gastrointestinal track after the oral administration (Haghighi et

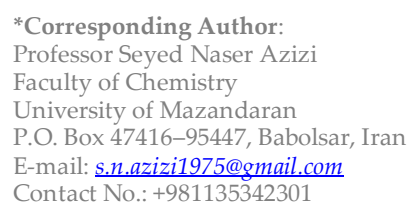

al., 2013). The recommended dosage of cetirizine in adults and children over the age of 12 is one $10 \mathrm{mg}$ tablet daily (Spencer et al., 1993). To the best of our knowledge, so far there have been no reports on optimization for preparation of synthetic nanozeolite sodalite as a potential carrier for delivery of cetirizine and our synthesis method for nanozeolite sodalite is new.

\section{MATERIALS AND METHODS}

\section{Materials}

Natural perlite as Si source was purchased from Afrazand Corporation. The source of perlite was from Semnan, Iran. Sodium aluminate as Al source was purchased from Prolab BDH. Cetirizine was obtained from Pro Ventus life corporation, india. Sodium dihydrogen phosphate and hexadecyltrimethylammonium bromide, all analytical grade, from Fluka (Munich, Germany), disodium hydrogen phosphate from Merck (Germany).

\section{Equipment}

X-ray diffraction (XRD) patterns were recorded on a Bruker AXS D8 Advance X-ray diffractometer (Bruker, Germany) with $\mathrm{Cu} \mathrm{K} \alpha$ radiation $(\lambda 1 / 41.5418 \AA$ ). Size distribution of nanozeolite was performed on scanning electron microscope (SEM). The FT-IR spectra $\left(4000-400 \mathrm{~cm}^{-1}\right)$ in $\mathrm{KBr}$ were recorded using an FT-IR spectrometer (Tensor 27-Bruker). UV-Vis spectrophotometer (Cambridge, UK) was used for determination of concentrations of drug.

\section{Synthesis of nanozeolite}

For synthesis of nanozeolite, $9.8 \mathrm{~g}$ of perlite was dissolved in $100 \mathrm{ml}$ alkaline solution of $\mathrm{NaOH} 0.215 \mathrm{M}$ (solution A). The mixture was stirred for 4 hour at $100^{\circ} \mathrm{C}$. Then, the mixture was filtered and the filtrate was used to synthesize nanozeolite. Then $0.768 \mathrm{~g}$ sodium aluminate was added to $15 \mathrm{ml}$ distilled water which contained of $0.26 \mathrm{~g}$ $\mathrm{NaOH}$ (solution B). Then solution $\mathrm{A}$ was added to solution $\mathrm{B}$ with hard shaking. The mixture was heated at $170^{\circ} \mathrm{C}$ for 18 hours in stainless steel reactor. Chemical composition of perlite was determined by XRF and it includes: $79.79 \% \mathrm{w} / \mathrm{w} \mathrm{SiO}_{2}, 10.66 \% \mathrm{Al}_{2} \mathrm{O}_{3}, 2.46 \% \mathrm{Na}_{2} \mathrm{O}$, $4.67 \% \mathrm{~K}_{2} \mathrm{O}, 0.06 \% \mathrm{MnO}, 0.67 \% \mathrm{Fe}_{2} \mathrm{O}_{3}, 0.20 \% \mathrm{MgO}, 0.01 \%$ $\mathrm{P}_{2} \mathrm{O}_{5}, 0.04 \% \mathrm{SO}_{3}, 1.34 \% \mathrm{CaO}, 0.10 \% \mathrm{TiO}_{2}, 1.31 \%$ L.O.I. 
<smiles>O=C(O)COCCN1CCN(C(c2ccccc2)c2ccc(Cl)cc2)CC1</smiles>

Figure 1: Chemical structure of cetirizine.

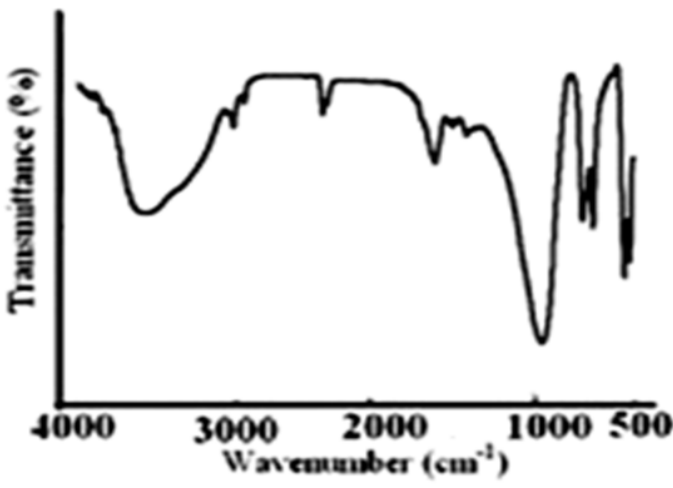

Figure 2: FT-IR spectrum of the synthesized nanozeolite sodalite.

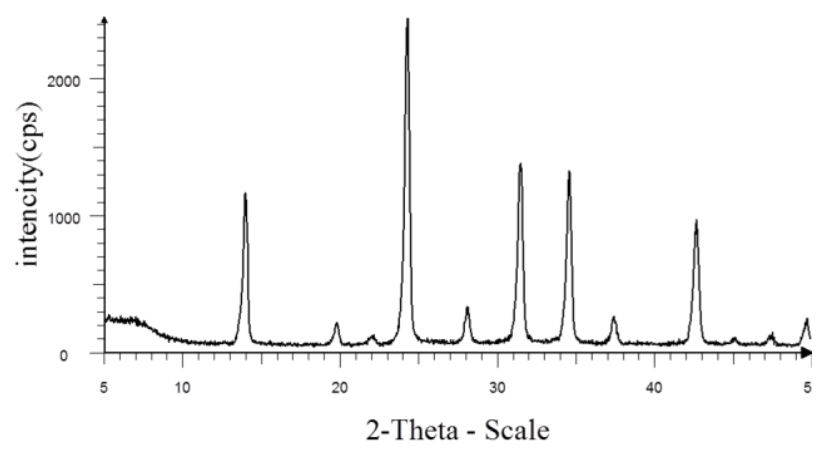

Figure 3: The XRD pattern of the synthesized nanozeolite sodalite.

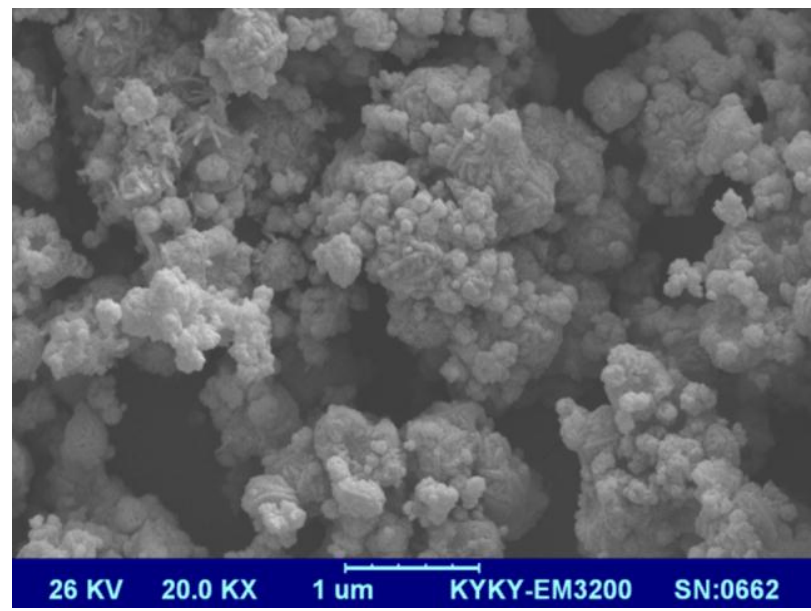

Figure 4: SEM image of synthesized nanozeolite sodalite.

\section{Modification of nanozeolite}

Due to the net negative charge on the framework, nanozeolites usually have little or no affinity for anions and exhibit low adsorption for organics in aqueous solution. To change the surface properties, one modification method widely employed is to use organic surfactants (Wang and Peng, 2010). Adsorption ability of modified nanozeolite was already proven for Cetirizine. To prepare the modified nanozeolite, $200 \mathrm{mg}$ of synthetic nanozeolite sodalite was added to $50-\mathrm{mL}$ aqueous solution of the cationic surfactant (HDTMAB) at concentration $(10 \mathrm{mmol} / \mathrm{L})$ in polyethylene bottle. The sample was stirred for $24 \mathrm{~h}$ at room temperature. The suspension was centrifuged at $10000 \mathrm{rpm}$ for $15 \mathrm{~min}$. Surface-modified sample was then washed with excess amounts of water until no foam was formed by shaking the supernatant. The prepared modified nanozeolite was air-dried for $72 \mathrm{~h}$ (Nezamzadeh-Ejhieh and Tavakoli-Ghinani, 2014).

\section{Drug loading}

Tests determining adsorption of Cet by prepared modified nanozeolite was carried out in batch experiments at room temperature. Stock solution of the drug in the concentration $100 \mathrm{mg} / \mathrm{L}$ in three phosphate buffer solutions at $\mathrm{pH} \mathrm{4,5}$ and 6 were prepared. Note that the adsorption of drug was favored at $\mathrm{pH}<\mathrm{pHzPC}(\mathrm{pH}$ at the potential of zero charge) (Mall et al., 2006). pHzPC measured using the $\mathrm{pH}$ drift method (Lopez-Ramon et al., 1999). The $\mathrm{pH} 4$ is under $\mathrm{pHzPC}$ and $\mathrm{pH} 6$ is above $\mathrm{pHzPC}$ for nanozeolite. Then $200 \mathrm{mg}$ of modified nanozeolite was soaked with $25 \mathrm{ml}$ of each 3 buffer drug solutions under continuous stirring at $250 \mathrm{rpm}$ at room temperature. After different times the sample was centrifuged $15 \mathrm{~min}$ at 10000 $\mathrm{rpm}$. Supernatant was used for determination of the drug. The initial and final concentration of drug was determined by UV-Vis spectrophotometer (Krajišnik et al., 2011).

\section{In-vitro drug release}

In-vitro release studies were performed in simulated body conditions according to references (Yang et al., 2006; Liu et al., 2013) with slight modification. Three buffered solutions with different $\mathrm{pH} 1.2$ (stomach), 6.8 (intestine) and 7.2 (blood) were selected for release medium and the temperature was precisely controlled at $37^{\circ} \mathrm{C}$. Cet loading into the nanozeolite was achieved as follows: $1 \mathrm{~g}$ of modified nanozeolite sodalite was soaked at $\mathrm{pH} 4$ for 120 min, at room temperature, under continuous stirring and in $100 \mathrm{ml}$ solution of $100 \mathrm{ppm}$ of Cet. Then the solution was filtered and the solid was air-dried for $24 \mathrm{~h}$.

Then, $200 \mathrm{mg}$ of Cet loaded modified nanozeolite sodalite as a nanocarrier was immersed into $20 \mathrm{~mL}$ of each buffered solution with magnetic stirring. After 2, 4 and 6 hours the samples were centrifuged $15 \mathrm{~min}$ at $10000 \mathrm{rpm}$. Supernatants were used for determination of the drug. The initial and final concentrations of drug were determined by UV-Vis spectrophotometer.

\section{RESULTS AND DISCUSSION}

\section{Characterization}

FT-IR spectrum of the synthesized nanozeolite is illustrated in (figure 2). The original assignments of the main IR bands were as follows: internal tetrahedral $1250-920 \mathrm{~cm}^{-1}$, pore opening vibrations; $1150-1050 \mathrm{~cm}^{-1}$, double ring $650-500$ $\mathrm{cm}^{-1}$. The most important peak in the region from 500 to 600 $\mathrm{cm}^{-1}$ is related to the presence of the double ring $\left(\mathrm{D}_{4} \mathrm{R}\right)$ that is characteristic in the nanozeolites (Breck, 1974). Sharp peaks corresponding to the water deformation mode at $\sim 1650 \mathrm{~cm}^{-1}$ and $3500 \mathrm{~cm}^{-1}$ appears in the spectra. 


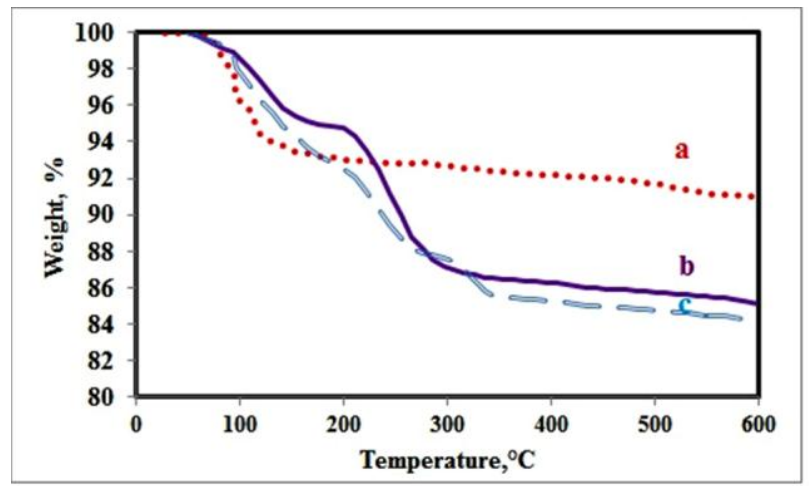

Figure 5: TGA thermograms of nanozeolite sodalite (a), modified nanozeolite sodalite (b) and modified nanozeolite sodalite with drug loaded (c).

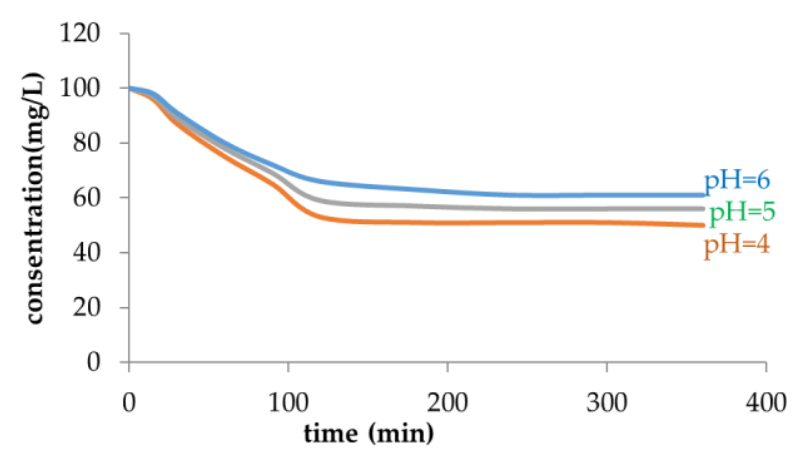

Figure 6: Effect of time and $\mathrm{pH}$ on the adsorption of Cetirizine.

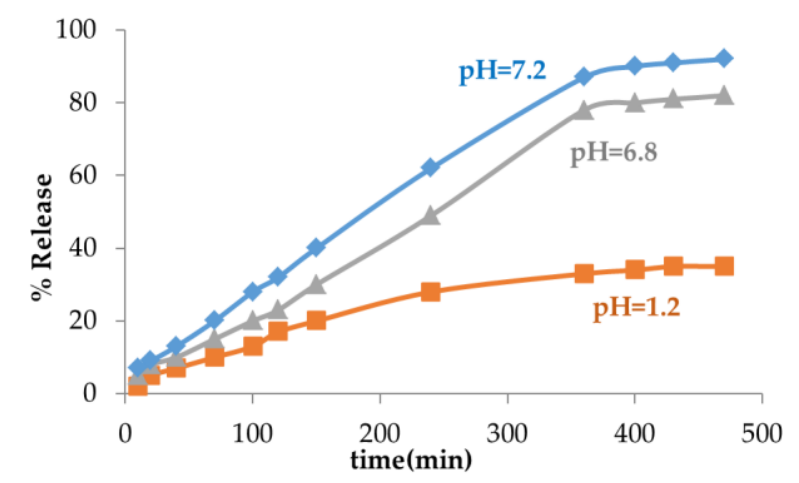

Figure 7: Cetirizine release profiles in different $\mathrm{pH}(1.2,6.8$ and 7.2) at $37^{\circ} \mathrm{C}$.

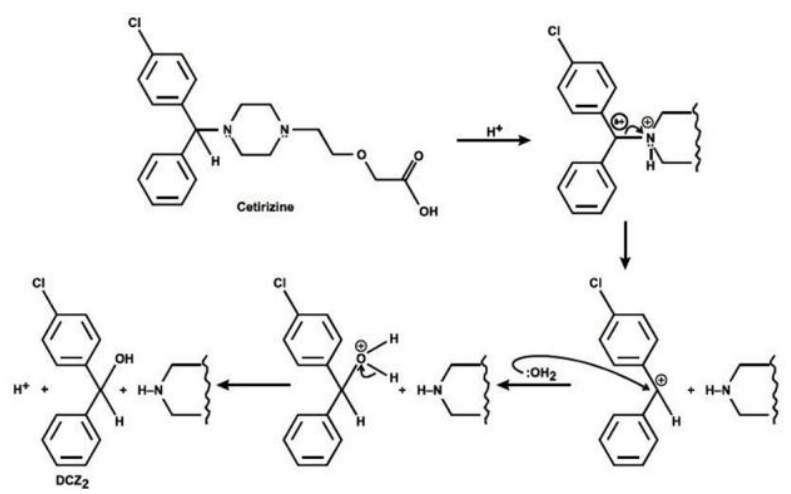

Figure 8: Degradation of Cetirizine in acidic solution.
The XRD pattern of the synthesized sample is shown in (figure 3). According atlas of zeolite framework types and comparison this pattern with mother pattern indicated that this synthesized sample has the structure of nanozeolite sodalite (Treacy and Higgins, 2001).

The SEM image of the particles is shown in figure 4, which shows the morphology of synthesized zeolite with small particle size in range of $30-81 \mathrm{~nm}$.

\section{Thermogravimetry analysis}

Figure 5 shows TGA thermograms of nanozeolite sodalite (a), modified nanozeolite sodalite (b) and modified nanozeolite sodalite with drug loaded (c). The TGA profile (c) has three peaks of mass loss at 100, 220 and $260^{\circ} \mathrm{C}$, respectively assigned to the loss of water by the nanozeolite, the thermal decomposition of surfactant and removal of drug.

\section{Loading and release studies}

The drug concentration in aqueous phase was determined spectrophotometrically at $230 \mathrm{~nm}$ and it was calculated from the difference between the initial and final concentration in the aqueous supernatant after the equilibrium. The amount of drug adsorbed onto modified zeolite, $q_{t}$ $(\mathrm{mg} / \mathrm{g})$ at time $\mathrm{t}$ was calculated using following equation:

$$
q_{t}=\frac{\left(C_{0}-C_{T}\right) V}{M}
$$

where $\mathrm{C}_{0}(\mathrm{mg} / \mathrm{L})$ is the initial adsorbate concentration, $\mathrm{V}(\mathrm{L})$ the volume of the drug solution in the flask, $\mathrm{C}_{\mathrm{T}}(\mathrm{mg} / \mathrm{L})$ the drug concentration after time $t$ and $M(\mathrm{~g})$ is the mass of dry adsorbent that was used (Bhakta and Munekage, 2011; Hameed et al., 2009 ), adsorption results are shown in figure 6.

In order to investigate the potential of using nanocarrier as drug carrier, its release behavior was evaluated in three different buffered solutions with $\mathrm{pH}$ $1.2,6,8$ and 7.2 at $37^{\circ} \mathrm{C}$ and in-vitro release profiles of it was shown in figure 7 . Results show the release of drug, increases with $\mathrm{pH}$ and so a drug moves down the gastrointestinal tract from the stomach to the intestine, its release will increase.

According to the proposed mechanism of degradation of Cetirizine leading to $\mathrm{DCZ}_{2}$ (Chlorophenyl benzyl alcohol) (Kaur et al., 2014), in acidic solution (stomach), the amount of Cet is reduced (figure 8).

\section{CONCLUSION}

Our study displays that perlite is a suitable Si source for preparing of nanozeolite sodalite and this method is very fast and easy. Adsorption of Cetirizine on surface of modified nanozeolite sodalite was successful. The study on the nanozeolite discussed here demonstrates that this structure can be used effectively for carrier drug applications. This carrier can reduce toxicity and enhance therapeutic efficacy of drug, also can control release of drug in body.

\section{ACKNOWLEDGEMENT}

We are grateful to Dr. Farzaaneh Zaaeri from Faculty of Pharmacy at Tehran University of Medical Sciences for her kind assistant. 


\section{REFERENCES}

Bhakta, J. N., \& Munekage, Y. (2011). Mercury (II) adsorption onto the magnesium oxide impregnated volcanic ash soil derived ceramic from aqueous phase. International Journal of Environmental Research, 5(3), 585594.

Breck, D. W. (1974). Zeolite molecular sieves: structure, chemistry, and use (Vol. 4). New York: Wiley.

Colella, C. (1999). Natural zeolites in environmentally friendly processe and applications. Studies in surface science and catalysis, 125, 641-655. [DOI]

Garces, J. M. (1999). Observations on zeolite applications. In Proceedings of the 12th International Conference on Zeolites. Materials Research Society, Warrendale (pp. 551-566).

Haghighi, S., Shapouri, M. R., Amoli-Diva, M., Pourghazi, K., \& Afruzi, H. (2013). HPTLC-densitometric determination of cetirizine and montelukast analysis in combined tablet dosage forms. Iranian Journal of Pharmaceutical Research, 12(2), 303-309.

Hameed, H. B., Krishni, R. R., \& Sata, S. A. (2009). A novel agricultural waste adsorbent for the removal of cationic dye from aqueous solutions. Journal of hazardous materials, 162(1), 305-311. [DOI]

Kaur, P., Bansal, G., \& Singh, S. (2014). Stress Degradation Studies on Cetirizine Dihydrochloride and Development of Degradation Pathways. Internatioanal journal of pharmaceutical and chemical sciences, 3, 809819.

Krajišnik, D., Daković, A., Milojević, M., Malenović, A., Kragović, M., Bogdanović, D. B., \& Milić, J. (2011). Properties of diclofenac sodium sorption onto natural zeolite modified with cetylpyridinium chloride. Colloids and Surfaces B: Biointerfaces, 83(1), 165-172. [DOI]

Kralj, M., \& Pavelic, K. (2003). Medicine on a small scale. EMBO reports, 4(11), 1008-1012. http://dx.doi.org/10.1038/sj.embor.7400017

Liu, W., Selomulya, C., \& Chen, X. D. (2013). Design of polymeric microparticles for $\mathrm{pH}$-responsive and time-sustained drug release. Biochemical Engineering Journal, 81, 177-186. [DOI]

Lopez-Ramon, M. V., Stoeckli, F., Moreno-Castilla, C., \& Carrasco-Marin, F. (1999). On the characterization of acidic and basic surface sites on carbons by various techniques. Carbon, 37(8), 1215-1221. [DOI]

Mall, I. D., Srivastava, V. C., Kumar, G. V. A., \& Mishra, I. M. (2006) Characterization and utilization of mesoporous fertilizer plant waste carbon for adsorptive removal of dyes from aqueous solution. Colloids and Surfaces A: Physicochemical and Engineering Aspects, 278(1), 175-187. [DOI]
Naber, J. E, De Jong K. P Stork, W. H. J Kuipers, H. P. C. E, \& Post, M. F. M. (1994). Industrial applications of zeolite catalysis. Studies in surface science and catalysis, 84, 2197-2219. [DOI]

Nezamzadeh-Ejhieh, A., \& Tavakoli-Ghinani, S. (2014). Effect of a nanosized natural clinoptilolite modified by the hexadecyltrimethyl ammonium surfactant on cephalexin drug delivery. Comptes Rendus Chimie, 17(1), 49-61. [DOI]

Pavelic, E. M. (1980). Molecular sieve zeolite technology-the first twentyfive years. Pure and applied chemistry, 52(9), 2191-2211. [DOI]

Rimoli, M. G., Rabaioli, M. R., Melisi, D., Curcio, A., Mondello, S., Mirabelli, R., \& Abignente, E. (2008). Synthetic zeolites as a new tool for drug delivery. Journal of Biomedical Materials Research Part A,87(1), 156164. [DOI]

Sersale, R. (1985). Natural zeolites: processing, present and possible applications. Studies in Surface Science and Catalysis, 24, 503-512. [DOI]

Spencer, C. M., Faulds, D., \& Peters, D. H. (1993). Cetirizine. Drugs, 46(6) 1055-1080. [DOI]

Suri, S. S., Fenniri, H., \& Singh, B. (2007). Nanotechnology-based drug delivery systems. Journal of Occupational Medicine and Toxicology, 2(1), 16. [DOI]

Treacy, M. M. J., \& Higgins, J. B. (2001). Collection of simulated XRD powder patterns for zeolites. Published on behalf of the Structure Commission of the 'International Zeolite Association'. Powder Patterns, 203, 204.

Wang, S., \& Peng, Y. (2010). Natural zeolites as effective adsorbents in water and wastewater treatment. Chemical Engineering Journal, 156(1), 11-24. [DOI]

Wilczewska, A. Z., Niemirowicz, K., Markiewicz, K. H., \& Car, H. (2012) Nanoparticles as drug delivery systems. Pharmacological reports, 64(5), 1020-1037. [DOI

Yang, J., Park, S. B., Yoon, H. G., Huh, Y. M., \& Haam, S. (2006).

Preparation of poly $\varepsilon$-caprolactone nanoparticles containing magnetite for magnetic drug carrier. International journal of pharmaceutics, 324(2), 185-190. [DOI 